\title{
A aplicação da técnica multivariada (PCA e HCA) em dados microbiológicos e físico-químicos de méis comercializados em Cachoeira do Ararí e Salvaterra - PA
}

The application of the multivariate technique (PCA and HCA) in data microbiological and physical-chemical of honeys marketed in Waterfall Ararí and Salvaterra - PA

\author{
P. W. P. Gomes ${ }^{1}$; J. D. E. Reis ${ }^{1}$; D. S. C. Silva ${ }^{1}$; A. P. A. Costa ${ }^{1}$; B. V. Malato ${ }^{1}$ \\ A. J. B. Muribeca ${ }^{2}$; P. W. P. Gomes ${ }^{2 *}$ \\ ${ }^{1}$ Grupo de pesquisa sobre ciência e meio ambiente, Universidade do Estado do Pará, 68860-000, Salvaterra-PA, \\ Brasil \\ ${ }^{2}$ Programa de Pós-Graduação em Química da Universidade Federal do Pará, 66075-970, Belém-PA, Brasil
}

*wenderufpa@hotmail.com

(Recebido em 20 de outubro de 2016; aceito em 30 de junho de 2017)

\begin{abstract}
O mel é rico em monossacarídeos de glicose e frutose e vem sendo cada vez mais utilizado como alimento, medicamento e conservantes; tornando-se necessário definir padrões de qualidade para este produto. O presente trabalho investigou o perfil microbiológico e físico-químico de méis dos municípios de Cachoeira do Ararí, e Salvaterra - PA, afim de padronizar os dados através dos testes de componentes principais e de agrupamentos. Foram analisadas dez amostras, obtendo-se os valores médios para cinzas (0,38\%), acidez livre (28,77 meq.kg-1), umidade $(22,25 \%)$ e cor com predominante âmbar-escuro (60\%). Para bolores e leveduras, 20\% das amostras estavam em acordo com a legislação nacional. A aplicação da técnica multivariada (PCA) aos parâmetros físico-químicos teve variância total 87,73\%, onde CP1 apresentou forte influência entre os parâmetros cor e cinzas e a CP2 expressou correlações entre acidez e umidade. Considerando a influência da discriminação geográfica dos municípios, a análise (HCA) apresentou dois grupos distintos por grau de similaridade, com a menor distância euclidiana para o grupo I. A aplicação da técnica multivariada (PCA) aos parâmetros microbiológicos demonstrou maior agrupamento para as amostras do município de Cachoeira do Ararí, comprovando a variância de 56,78\% (CP1) de aspectos fidedignos de cada município. O dendograma (HCA) confirma os aspectos discutidos em scores e loadings. A partir desses resultados, percebe-se a importância das análises estatísticas para determinar padrões de qualidade do mel de regiões distintas, uma vez que vários fatores influenciam na obtenção e comercialização deste produto.

Palavras-chave: Mel de abelha, Análises Microbiológicas, Análises Físico-químicas, técnicas multivariadas (PCA e HCA).
\end{abstract}

Honey is rich in monosaccharides glucose and fructose and is being increasingly used as food, medicine, and preservatives, which makes it necessary to set standards for the quality of this product. The present work investigated the profile of the microbiological and physical-chemical honeys in the municipalities of Cachoeira do Ararí, and Salvaterra - PA, in order to standardize the data through the tests of main components and grouping. Were analyzed ten samples, obtaining the average values for ash $(0.38 \%)$, free acidity (28,77 meq.kg-1), humidity $(22.25 \%)$ and color with dominant amber-dark (60\%). For yeasts and molds, $20 \%$ of the samples were in accordance with national legislation. The application of the multivariate technique (PCA) to the physical-chemical parameters had variance total $87.73 \%$, where CP1 showed a strong influence between the parameters of color and ashes, the CP2 expressed correlations between acidity and moisture. Considering the influence of the geographical breakdown of the municipalities in the analysis (HCA) showed two distinct groups by degree of similarity, with the smallest distance to the group I. The application of the multivariate technique (PCA) to the microbiological criteria demonstrated a higher grouping for the samples in the municipality of Cachoeira do Ararí, proving the variance of 56.78\% (CP1) aspects trusted each municipality, the dendograma (HCA) confirms the aspects discussed in scores and loadings. From these results, we can notice the importance of the statistical analysis to determine quality standards of honey from different regions, because several factors influence in the obtaining and marketing of this product.

Keywords: Honey bee, Microbiological Analysis, Physical-chemical Analysis, techniques multivariate (PCA and HCA). 


\section{INTRODUÇÃO}

A relação harmônica entre plantas e insetos traz benefícios para ambos: as flores disponibilizam néctar e pólen e, em troca, são polinizadas, o que garante a continuidade de gerações de muitas espécies, prevenindo a extinção genética desses indivíduos [1].

A apicultura traz consigo um encargo bastante promissor, pois permite a criação de um elo entre os aspectos sociais, econômicos e ambientais, propiciando a conservação dos ecossistemas em que é implantada. Esse tipo de prática não exige a ocupação de áreas extensivas e nem interfere em outros tipos de atividades. Os principais problemas enfrentados pela apicultura no Brasil resumem-se às abelhas europeias, que possuem uma fraca produção apícola bem como intolerância a drogas. Em curto período de trabalho, esses problemas foram resolvidos à medida que a introdução de abelhas africanizadas se intensificou. Assim, aumentou-se a produção e sua valorização no mercado interno cresceu de tal maneira que o Brasil se enquadrou como um dos grandes produtores apícolas, que também são valorosos inclusive no mercado internacional [2].

$\mathrm{O}$ mel é definido como um produto que é processado pelas abelhas, onde se utiliza como matéria-prima o néctar que é extraído das flores, mel floral ou secreções açucaradas que fluem de plantas, o mel melato. Após a coleta, esse material é convertido em mel a partir da desidratação e adição de substâncias enzimáticas advinda das abelhas [3]. Este alimento contém diversas moléculas de interesse como flavonoides, ácidos fenólicos, vitaminas e glicídios com potencial probiótico, sendo apreciados por suas propriedades sensoriais e consumidos na forma pura ou como ingrediente na indústria alimentícia [4].

O monitoramento da qualidade deste produto é indispensável, uma vez que este vem sendo cada vez mais utilizado para fins alimentícios e em associações medicinais devido as suas propriedades farmacológicas; sendo o mel adotado como conservantes de muitos produtos de horticultura, prevenindo a oxidação [3]. A legislação brasileira vigente de 2000 prerroga apenas padrões para o mel de abelhas melíferas, onde estabelece as condições nutricionais e sanitárias mínimas que o produto deve apresentar para que se torne ideal e seguro para o consumo humano, contudo esse mel é suscetível às contrafações que ocorrem principalmente com adição de produtos açucarados [13].

A microbiota, por sua vez, é bastante variada pois, além dos micro-organismos incluídos durantes as etapas de processamento realizado pelas abelhas, também existe a contaminação microbiológica que é veiculada em virtude da prática indiscriminada e descuidada durante a extração e beneficiamento do mel [5].

A Associação Brasileira dos Exportadores de Mel, registrou uma produção nacional de aproximadamente 24,2 toneladas de mel no ano de 2016, mantendo o país no quadro dos maiores produtores mundiais [6].

As análises de qualidade do mel comercializado possuem diversas aplicações quando se trabalha com determinadas variáveis e parâmetros, garantindo explicações claras, objetivas e com confiança de $95 \%$ na descrição e correlação entre as variáveis/fatores de influência para agrupamentos, além de perda/aumento em grau de similaridade para os resultados. Ressalta-se que os exames microbiológicos são de fundamental importância para determinar a qualidade deste produto, tendo em vista o seu consumo humano para fins alimentícios e também medicinais, como já vem usado em atividades antimicrobianas e bioativas, segundo trabalhos recentes descrito por Sousa et al. (2016) [7] e Osés et al. (2015) [8], respectivamente. Dessa maneira, o presente trabalho investigou o perfil microbiológico, físico-químico e desenvolver estatística explicativa através das técnicas multivariadas (PCA e HCA) de méis obtidos do setor comercial dos municípios de Cachoeira do Ararí e Salvaterra, localizados no arquipélago do Marajó, Estado do Pará.

\section{MATERIAL E MÉTODOS}

\section{1. ÁREA DE ESTUDO E PROCEDÊNCIA DAS AMOSTRAS}

O município de Cachoeira do Arari ( ${ }^{\circ} 0^{\prime} 16^{\prime \prime} \mathrm{Sul}, 48^{\circ} 57^{\prime} 27^{\prime \prime}$ Oeste), localizado no Estado do Pará e pertencente à mesorregião do Marajó e a microrregião do Arari (Figura 1), está situado a 
5 metros de altitude. Em estimativa do IBGE, sua população em 2016 foi de 22.786 habitantes [9]. O município de Salvaterra ( $0^{\circ} 45^{\prime} 32^{\prime \prime}$ Sul, 48 30' 44" Oeste), também no Estado do Pará e pertencente à mesorregião do Marajó e a microrregião do Arari (Figura 1), está situado a 4 metros de altitude. O IBGE estimou sua população no ano de 2016 em 22.740 habitantes [9].

Realizou-se o estudo com uma representatividade de dez amostras de méis de abelhas dos municípios de Cachoeira do Arari e de Salvaterra fomentadas através de compra no comércio dos referidos municípios. Após a obtenção das amostras, estas foram conduzidas aos Laboratórios de Ciências Naturais e Microbiologia da Universidade do Estado do Pará, Campus XIX-Salvaterra, para estudo dos parâmetros físico-químicos e análises microbiológicas.

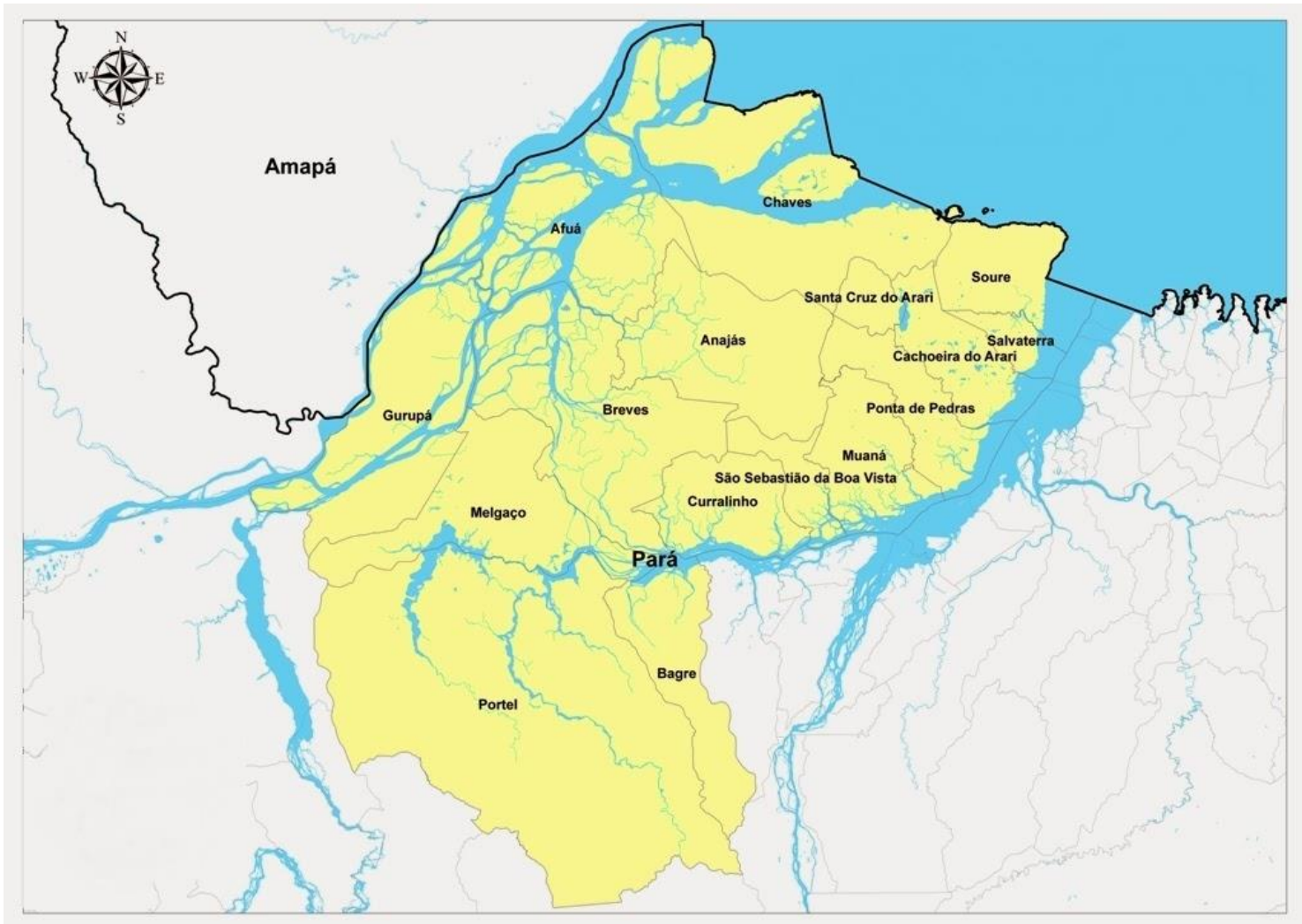

Figura 1: Mapa descritivo do Arquipélago de Marajó. Fonte: Sistema de Informações Territoriais - SIT, o MDA (BRASIL, 2016).

\subsection{ANÁLISES FÍSICO-QUÍMICAS}

\subsubsection{Determinação de umidade}

A determinação de umidade do mel foi obtida em triplicata, realizada de maneira indireta através do índice de refração. Colocou-se em torno de uma gota de mel sobre o prisma do refratômetro, com o auxílio de bastão de vidro e posteriormente fez-se a leitura na escala do índice de refração e transformou-se em percentual de umidade de acordo com a tabela de Chataway.

\subsubsection{Acidez total}

A acidez total foi determinada pelo método titulométrico. Um total de $2 \mathrm{~g}$ de mel foi dissolvido em $15 \mathrm{ml}$ de água destilada e esta solução foi titulada com solução de $0,05 \mathrm{M} \mathrm{NaOH}$ até que o pH atingisse a marca de 8,5. A formula utilizada para quantificação foi Aci= V.fc.M.1000/Ma, onde $\mathrm{V}$ é o volume (em mL) de $\mathrm{NaOH}$ mol L ${ }^{-1}$ gasto na titulação; fc é o fator de correção da solução de $\mathrm{NaOH} 0,1 \mathrm{~mol} \mathrm{~L}^{-1}$; $\mathrm{M}$ é a concentração de solução de $\mathrm{NaOH}$ em mol/L; e Ma é a massa da amostra. 


\subsubsection{Determinação de cor}

As cores para as amostras de méis foram determinadas segundo Bianchi (1981) [10], que propõe a leitura de uma solução de mel em água deionizada $50 \%(\mathrm{~m} / \mathrm{v})$ a absorbância de $635 \mathrm{~nm}$. Posteriormente os resultados obtidos foram convertidos em escala de Pfund.

\subsubsection{Determinação de cinzas}

Os resíduos minerais fixos nas amostras de méis foram determinados com auxílio de um forno mufla (Zezimaq $\left.{ }^{\circledR}\right)$, o princípio baseia-se na calcinação de toda matéria orgânica em temperatura elevada. Fez-se desidratação dos cadinhos de porcelana em estufa à $105^{\circ} \mathrm{C}(1 \mathrm{~h})$ até atingir peso constante, posteriormente incinerou-se uma massa aproximadamente de $5 \mathrm{~g}$ de mel em chapa aquecedora e levou ao forno mufla à $550^{\circ} \mathrm{C}$ por 5 horas utilizando programação linear de $2{ }^{\circ} \mathrm{C} / \mathrm{min}$ [11]. Por fim, o resíduo branco (cinzas) foi quantificado através da equação (\% cinzas $=\mathrm{P}_{\text {final }}-$ $\left.\mathrm{P}_{\text {inicial }} / \mathrm{Pa} \times 100\right)$, onde, $\%$ cinzas $=$ Resíduo mineral, $\mathrm{P}_{\text {final }}=$ peso do cadinho + resíduo, $\mathrm{P}_{\text {inicial }}=$ peso do cadinho e $\mathrm{P}_{\text {amostra }}=$ Peso da amostra.

\subsection{ANÁLISES MICROBIOLÓGICAS}

Para as análises de fungos utilizou-se o método descrito nos "Procedimentos para a contagem de colônias" [12]. Fez-se emplacamento em superfície com meio sólido Ágar-batata-glicose (4 $\mathrm{g} / \mathrm{L}$ extrato de batata; $20 \mathrm{~g} / \mathrm{L}$ de glicose e $15 \mathrm{~g} / \mathrm{L}$ de ágar). As placas foram incubadas em estufa microbiológica à temperatura de $25^{\circ} \mathrm{C}$ por 5 dias e os resultados expressos em UFC/g.

A determinação de coliformes totais e termotolerantes foi realizada pelo método de fermentação em tubos múltiplos, utilizando série de três tubos. Para a determinação do NMP de coliformes se empregou a Tabela para Número Mais Provável (NMP) de acordo com Brasil (2003) [12].

\subsection{ANÁLISES MULTIVARIADAS (PCA E HCA)}

Os resultados obtidos foram analisados e interpretados através do o software STATISTICA 8.0, empregando análise estatística multivariada: Análise de Componentes Principais (PCA) e Análise de Agrupamento (HCA).

\section{RESULTADOS E DISCUSSÃO}

\subsection{ANÁLISES FÍSICO-QUÍMICOS}

Os valores (média \pm desvio padrão) encontrados para os parâmetros físico-químicos analisados das 10 amostras de mel de abelha estão estabelecidos na Tabela 1, onde se constituiu um padrão médio para os parâmetros analisados. Ressalta-se que os mesmos foram comparados com a legislação brasileira [13] e as internacionais [14] e [19], onde estabelecem valores padrões para o controle de qualidade do produto. 
Tabela 1. Parâmetros físico-químicos ( ${ }^{a}$ média $\pm{ }^{b}$ desvio padrão) das 10 amostras de méis produzidos nos municípios de Salvaterra e Cachoeira do Ararí no Estado do Pará. Amo: Amostra; S: Salvaterra; CA:

Cachoeira do Ararí; Aci: Acidez livre (meq. $\left.\mathrm{kg}^{1}{ }^{1}\right)$; Umi: Umidade (\%); Cin: cinzas (\%); Cor

(Abs635); 'Legislação Brasileira (BRASIL, 2000; [13]); ${ }^{2}$ Legislação Internacional (CODEX, 2001; [14]);

${ }^{3}$ Legislação Internacional (MERCOSUL, 1994; [19]); * ausência de limites nas legislações;(a unidade do desvio está de acordo com a unidade do parâmetro).

\begin{tabular}{ccccc}
\hline Amo & Cin & Aci & Umi & Cor \\
\hline $01 \mathrm{~S}$ & $0,33 \pm 0,20$ & $53,03 \pm 0,20$ & $19,35 \pm 2,88$ & 606,62 (Âmbar-escuro) \\
$02 \mathrm{~S}$ & $0,99 \pm 0,01$ & $30,28 \pm 0,15$ & $22,05 \pm 2,88$ & 882,62 (Âmbar-escuro) \\
$03 \mathrm{~S}$ & $0,19 \pm 0,20$ & $27,00 \pm 0,05$ & $29,45 \pm 2,88$ & 79,85 (Âmbar-claro) \\
$04 \mathrm{~S}$ & $0,55 \pm 0,04$ & $35,90 \pm 0,05$ & $24,56 \pm 0,01$ & 147,24 (Âmbar-escuro) \\
$05 \mathrm{~S}$ & $0,93 \pm 0,01$ & $28,73 \pm 0,10$ & $24,36 \pm 0,01$ & 246,95 (Âmbar-escuro) \\
$06 \mathrm{CA}$ & $0,20 \pm 0,01$ & $37,19 \pm 0,05$ & $22,36 \pm 0,01$ & 80,8 (Âmbar-claro) \\
$07 \mathrm{CA}$ & $0,25 \pm 0,23$ & $11,32 \pm 0,02$ & $22,18 \pm 0,01$ & 171,93 (Âmbar-escuro) \\
$08 \mathrm{CA}$ & $0,05 \pm 0,01$ & $25,86 \pm 0,05$ & $22,97 \pm 0,01$ & 180,84 (Âmbar-escuro) \\
$09 \mathrm{CA}$ & $0,27 \pm 0,08$ & $29,06 \pm 0,02$ & $16,01 \pm 0,01$ & 86,01 (Âmbar) \\
$10 \mathrm{CA}$ & $0,09 \pm 0,01$ & $9,35 \pm 0,02$ & $19,29 \pm 0,01$ & 65,1 (Âmbar-claro) \\
\hline Média & 0,38 & 28,77 & 22,25 & 254,79 \\
\hline Min & 0,05 & 9,35 & 16,01 & 65,1 \\
\hline Max & 0,99 & 53,03 & 29,45 & 882,62 \\
\hline${ }^{1}$ Lesgilação & $\leq 0,6$ & $\leq 50,0$ & $\leq 20,0$ & $*$ \\
\hline${ }^{2}$ Lesgilação & $*$ & $\leq 50,0$ & $\leq 20,0$ & $*$ \\
\hline${ }^{3}$ Lesgilação & $\leq 0,6$ & $\leq 50,0$ & $\leq 20,0$ & $*$
\end{tabular}

\subsubsection{Umidade}

Os índices de umidade encontrados nas amostras dos méis estudados variaram de 16,01\% a $29,45 \%$ com média de (22,25\%), apresentando um percentual de $70 \%$ das amostras acima do teor de umidade aceitável segundo os padrões da Legislação nacional [13] e as internacionais [14, 19], onde estabelecem o limite máximo de $20 \%$. Entretanto, a literatura descreve resultados realizados com pesquisadores de diferentes tipos que mel que são superiores aos encontrados nesse trabalho $[20,21,22,23,24]$. Alguns fatores influenciam no aumento do teor de água nos méis, sendo o mais comum no Marajó o caráter úmido da região com fortes chuvas. Entretanto a centrifugação é um processo que também favorece a adsorção de água pela formação de uma grande superfície em relação ao volume inicial de mel e ainda o processo de fermentação que ocorre mais facilmente ocasionando produção de excesso de água aumentando a umidade do mel.

\subsubsection{Acidez}

Os valores de acidez total em meq. $\mathrm{Kg}^{-1}$ variaram de 9,35 a 53,03 (média de 28,77). Esses resultados mostraram que $90 \%$ das amostras analisadas estão em total acordo com os valores preconizados pela Legislação Nacional [13] e as internacionais [14, 19], onde o máximo permitido se equivale a 50 meq. $\mathrm{Kg}^{-1}$. A acidez é um fator que minimiza a proliferação de micro-organismos [25]. Modesto Jr. et al. (2014) [16], ao analisarem méis da cidade de Salvaterra - PA, encontraram valores similares e ressaltam que os resultados podem estar correlacionados com o processo de fermentação do mel.

\subsubsection{Cor}

As cores encontradas para as 10 amostras de mel de abelha analisadas, estão dentro dos padrões da legislação nacional [13], que estabelece uma cor que vai do branco-água até o âmbarescuro. A cor âmbar-escuro apresentou predominância nas amostras de ambos os municípios em 
estudo, com destaque para Salvaterra que apresentou um percentual igual a $80 \%$ para cor âmbarescuro de todas as amostras. Recentemente Borsato (2013) [26] encontrou 80,95\% de predominância para a cor âmbar-escuro das 08 amostras de méis provenientes do município de Curitiba, localizado no Estado do Paraná, propondo que a mesma pode estar relacionada com o tipo de flor, seja de laranjeira, eucalipto, etc.

\subsubsection{Cinzas}

Os percentuais de cinzas variaram de $0,05-0,99 \%$, ressalta-se que $20 \%$ do total de amostras $(02 \mathrm{~S}$ e $05 \mathrm{~S})$ apresentaram um percentual superior a $0,6 \%$, valor máximo determinado pela legislação. A média de cinzas nas amostras analisadas equivaleu a $0,38 \%$, sendo que $80 \%$ das amostras estão em total conformidade com o padrão estabelecido pela legislação brasileira. Santos et al. (2011) [27], ao investigar amostras de mel da cidade de Russas/CE, também registrou valores fora do padrão permitido, com variação de 0,02 a 2,67\% (média de 1,15\%). Almeida Filho et al. (2011) [28], analisaram oito amostras de mel obtidos da cidade paraibana de Pombal, e verificaram que $87,5 \%$ estavam em desacordo com a legislação, com uma variação de 0,58 a $1,41 \%$, com média de $0,9 \%$.

\subsection{ANÁLISES MICROBIOLÓGICAS}

Os resultados microbiológicos de bolores e leveduras observados, mostraram que $20 \%$ das 10 amostras está em acordo com a Normativa $n^{\circ} 11$ de 20 de outubro de 2000 do Ministério da

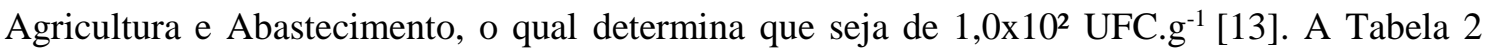
descreve os resultados de bolores e leveduras, na qual apenas as amostras 06 e 09 apresentam valores dentro do estabelecido pela legislação [13], sugerindo que os méis do município de Cachoeira do Ararí apresentam um melhor tratamento asséptico quando comparado aos méis comercializados em Salvaterra. Esses resultados, embora efêmeros, remetem às condições de higiene no beneficiamento e contaminação em torno das colmeias, que podem oferecer risco ao seu consumo por apresentarem irregularidade sanitária no processamento final do mel [2]. A Legislação Nacional [13] e Internacional [14] não dispõem análises que definam as propriedades microbiológicas do mel, mas advertem boas condições de higiene na manipulação e processamento.

Tabela 2: Discriminação microbiológica de bolores e leveduras das 10 amostras de méis analisadas nos municípios de Salvaterra e Cachoeira do Ararí (Pará).

\begin{tabular}{cccc}
\hline $\begin{array}{c}\text { Amostra de } \\
\text { Salvaterra }\end{array}$ & $\begin{array}{c}\text { Bolores e } \\
\text { Leveduras } \\
\text { (UFC } * * / g)\end{array}$ & $\begin{array}{c}\text { Amostra de } \\
\text { Cachoeira do Ararí }\end{array}$ & $\begin{array}{c}\text { Bolores e } \\
\text { Leveduras } \\
\text { (UFC**/g) }\end{array}$ \\
\hline $01 \mathrm{~S}$ & $4,0 \times 10^{4}$ & $06 \mathrm{CA}$ & $5,0 \times 10^{1}$ \\
$02 \mathrm{~S}$ & $2,5 \times 10^{4}$ & $07 \mathrm{CA}$ & $1,2 \times 10^{3}$ \\
$03 \mathrm{~S}$ & $1,5 \times 10^{4}$ & $08 \mathrm{CA}$ & $1,5 \times 10^{4}$ \\
$04 \mathrm{~S}$ & $1,1 \times 10^{3}$ & $09 \mathrm{CA}$ & Ausente \\
$05 \mathrm{~S}$ & $4,0 \times 10^{4}$ & $10 \mathrm{CA}$ & $1,7 \times 10^{3}$ \\
\hline
\end{tabular}

Segundo Fortuna et al. [15], está análise microbiológica é essencial em avaliações higiênicosanitárias do produto, definindo os padrões na qualidade de processamento, manipulação e validade comercial. Modesto Junior et al. [16], também encontrou resultados parecidos com achados neste estudo, mostrando que $70 \%$ das amostras apresentaram contaminação por fungos e leveduras. Gomes et al. (2014) [17] ao analisarem 12 amostras de méis provindas dos municípios de Soure e Salvaterra, encontraram apenas duas amostras com unidades formadoras de colônia, que são resultados inteiramente distintos dos valores propostos neste trabalho. Entretanto, ao comparar os resultados obtidos neste trabalho com os resultados encontrados por Neris et al. (2013) [18], sugere-se que os méis do município de Cachoeira do Ararí e Salvaterra têm 
contaminações atenuantes pois Neris et al. [18], ao analisarem o perfil microbiológico de méis do estado do maranhão, encontraram valores superiores a $738 \mathrm{UFC} / \mathrm{g}$ sendo considerados dentro de uma faixa não prejudicial ao consumo. As figuras 2A e 2B demonstram algumas das colônias de fungos encontradas no presente estudo.



Figura 2: Observação emplacas de petri dos resultados da análise de bolores e leveduras dos méis dos municípios de Salvaterra (A) e Cachoeira do Ararí (B), Pará.

Para os resultados de coliformes totais e coliformes termotolerantes, ressalta-se que não houve incidência em nenhuma das amostras analisadas de ambos os munícipios estudados, portanto os valores obtidos se fixaram-se no mínimo estabelecido pela legislação brasileira [13] equivalendo a $<3,00 \mathrm{NMP} / \mathrm{g}$ para todas as amostras.

\subsection{ANÁLISES ESTATÍSTICAS}

Para os parâmetros microbiológicos considerou-se a determinação de fungos, coliformes totais e termotolerantes que foram submetidos à avaliação de Análises Hierárquica de Agrupamentos (HCA) e de Componentes Principais (PCA). Este estudo proporcionou uma explicação clara e objetiva das correlações e variância das amostras de méis, uma vez que os agrupamentos apresentam indivíduos semelhantes entre si.

A figura 3 representa o gráfico de scores que delineia o agrupamento das amostras $03 \mathrm{~S}, 04 \mathrm{~S}$, 06CA, 07CA, 08CA, 09CA e 10CA. Nota-se que, do total de agrupamentos, $72 \%$ corresponde às amostras oriundas do município Cachoeira do Ararí; o que sugere de maneira clara e explicativa a correlação e semelhança entre as amostras com os aspectos geográficos do município de origem. Vale ressaltar que as amostras $03 \mathrm{~S}$ e $04 \mathrm{~S}$ (pertencentes ao município de Salvaterra) apresentaram forte semelhança ao perfil microbiológico das amostras de Cachoeira do Ararí, podendo esse fato estar relacionado à similaridade em algum aspecto (tipo de flor, néctar, hábitat e etc) da área de atuação das abelhas, ainda que em municípios com distribuição geográfica distinta. 


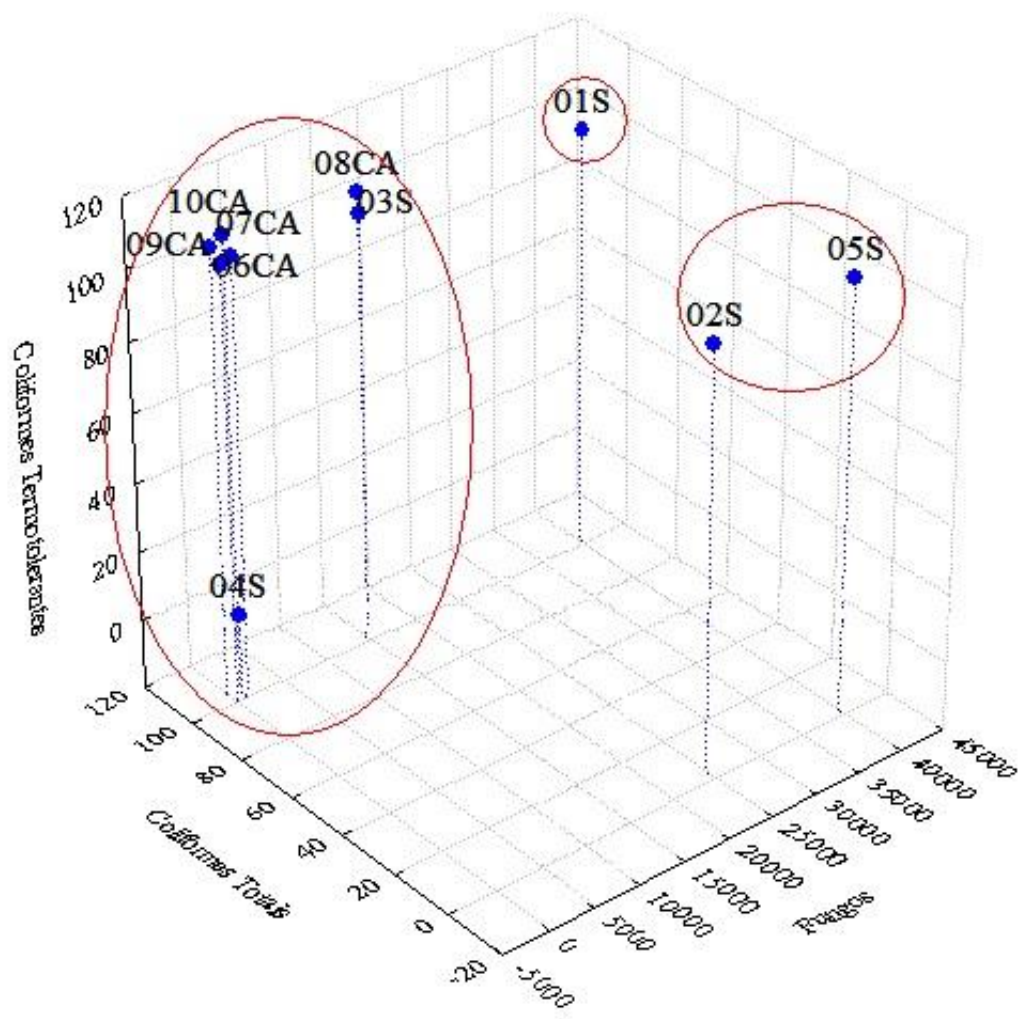

Figura 3: Gráfico dos scores para as 10 amostras de méis de Salvaterra e Cachoeira do Ararí, Pará.

Ratificando, o gráfico de loadings (Figura 4) demonstra que o notável agrupamento entre as amostras 03S, 04S, 06CA, 07CA, 08CA, 09CA e 10CA pode estar sendo influenciado tanto pelo aspecto quantitativo de fungos (bolores e leveduras) presente nas amostras de méis, onde correspondem a 56,78\% (CP1) da variância e covariância total. Esse grau de semelhança pode estar relacionado à forma com que o produto é tratado desde que é retirado da colméia até chegar à prateleira, o que demonstra que a qualidade e condições sanitárias adotadas nas técnicas de beneficiamento ainda são incipientes, situação ainda muito comum na região de estudo devido à falta de capacitação dos apicultores.

O dendograma (figura 5) confirma todos os aspectos já discutidos, destacando que a formação dos grupos, seja o que contém a maior quantidade de amostras $(03 \mathrm{~S}, 04 \mathrm{~S}, 06 \mathrm{CA}, 07 \mathrm{CA}$, 08CA, 09CA e 10CA) ou o menor (01S), apresentam suas similaridades peculiares segundo os perfis advindos do caráter geográfico, tipo de solo onde a vegetação se encontra, clima, flora e etc., fatores que influenciam diretamente e proporcionalmente quando se obtém um produto natural.

Para a avaliação físico-química, a análise hierárquica de agrupamentos (HCA) e dos componentes principais (PCA) utilizaram dados experimentais obtidos por meio de quatro parâmetros: acidez, cinzas, cor e umidade. $\mathrm{O}$ estudo multivariado possibilitou, durante o método indutivo, a obtenção de explicações claras e concisas de correlação e variância, quando submetidas ao agrupamento com indivíduos de características similares entre si.

Os resultados da variância proporcional mostraram que o primeiro componente principal (CP1) explica 60,91\% da variância total dos dados obtidos e a CP2 26,82\%. A somatória das CP1 e CP2 corresponde a 87,73\% do valor total de variação. Mardia et al. (1979) [29] explicaram que em uma análise de componentes principal onde os dois, ou três, primeiros componentes reúnem um valor percentual em geral acima de $70 \%$ da variação total, podendo ser considerado como um esclarecimento da variabilidade despontada entre as diferenças avaliadas. Apenas dois componentes principais foram satisfatórios para elucidar $87,73 \%$ da variância total disponível entre os parâmetros físico-químicos. Sendo assim, são considerados aceitáveis para delinear os resultados de variância e covariância total dos dados obtidos dos gráficos de scores e loadings. 
Através da análise do gráfico de scores (Figura 6), nota-se a formação de quatro agrupamentos entre as amostras, grupo I (06CA, 07CA e 10CA) e II (08CA e 09CA) discriminados na CP1, provenientes do município de Cachoeira do Ararí, e agrupamentos III (03S, 04S e 05S) e IV (01S e 02S), oriundos do município de Salvaterra.

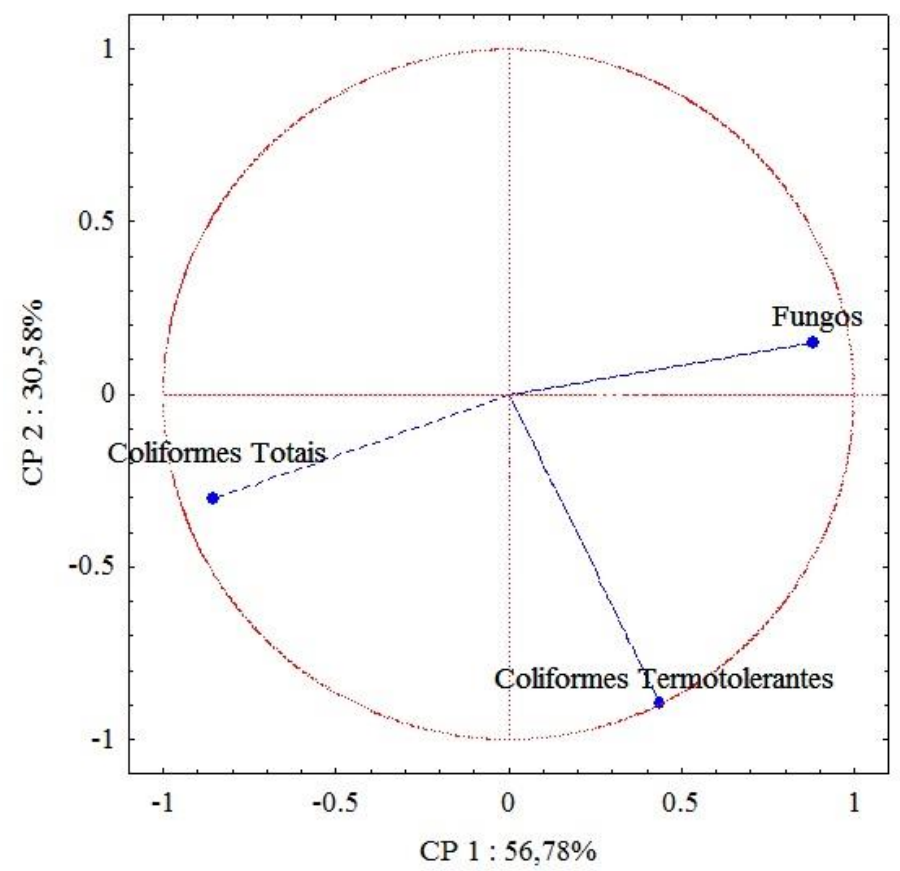

Figura 4: Gráfico de Loadings a partir dos principais componentes (3 parâmetros microbiológicos) das amostras de méis no Pará.



Figura 5: Dendograma utilizando a similaridade das 10 amostras de méis e os três parâmetros microbiológicos no Pará.

É perceptível que as amostras dos grupos I e II se encontram mais divergentes em seus respectivos agrupamentos, isso pode se dar ao fato de que as amostras apresentam um mel com 
características distintas, podendo estar relacionado com a sua origem floral, a quantidade de minerais e/ou a cor [30]. Este último parâmetro pode ser influenciado pelo armazenamento prolongado, incidência exaustiva de luz, reações enzimáticas, temperatura e processo de colheita impróprio, podendo assim causar o escurecimento do mel [31]. Entretanto, observa-se que os grupos III e IV apresentam proximidade mais significativa, sugerindo que estas amostras apresentam características semelhantes.



Figura 6: Gráfico dos scores para as 10 amostras de mel de Cachoeira do Arari e Salvaterra, Pará.

Através do gráfico dos loading (Figura 7) é possível observar a influência das variáveis sobre as amostras no gráfico de scores. O primeiro componente (CP1) apresentou um contraste entre os parâmetros cor e cinzas, porém percebe-se que os parâmetros de acidez e umidade, localizados no segundo componente (CP2), são caracterizados negativamente, podendo estar diretamente influenciados pela distribuição geográfica dos municípios estudados, o que torna esse fator um determinante no isolamento significativo das amostras. Além disso, estas distinções podem estar relacionadas ainda à qualidade dos méis, no que se refere ao tipo processamento, condições de extração e práticas apícolas [4].

A análise dos componentes principais (PCA) foi confirmada através do dendograma (Figura 8) utilizando a distância euclidiana, que se define como a análise hierárquica (HCA) para representar a aglomeração feita em uma escala de 0 a 100 e mostrar as similaridades entre as amostras agrupadas, estas por sua vez estão situadas na base do dendograma. Este gráfico é uma representação bidimensional de uma relação n-dimensional, o que inevitavelmente apresenta distorções quanto à similaridade [32].

Pode-se visualizar na Figura 8 que os primeiros agrupamentos ocorrem em uma baixa distância euclidiana, e alta similaridade: grupo I constituído pelas amostras $03 \mathrm{~S}, 04 \mathrm{~S}, 05 \mathrm{~S}$ e 08CA, grupo II pelos méis 01S, 02S, 06CA e 09CA e grupo III (composto por 07CA e 10CA), sendo que a menor distância é encontrada no grupo I. Além disso, é possível observar que estes grupos encontram-se bem separados. $\mathrm{O}$ agrupamento III (07CA e 10CA) está numa discriminação à parte do restante das amostras, podendo ser influenciados pelos potenciais distintos de flora apícola em diferentes raios de proximidade do apiário, como afirma Marochi (2011) [33]. 


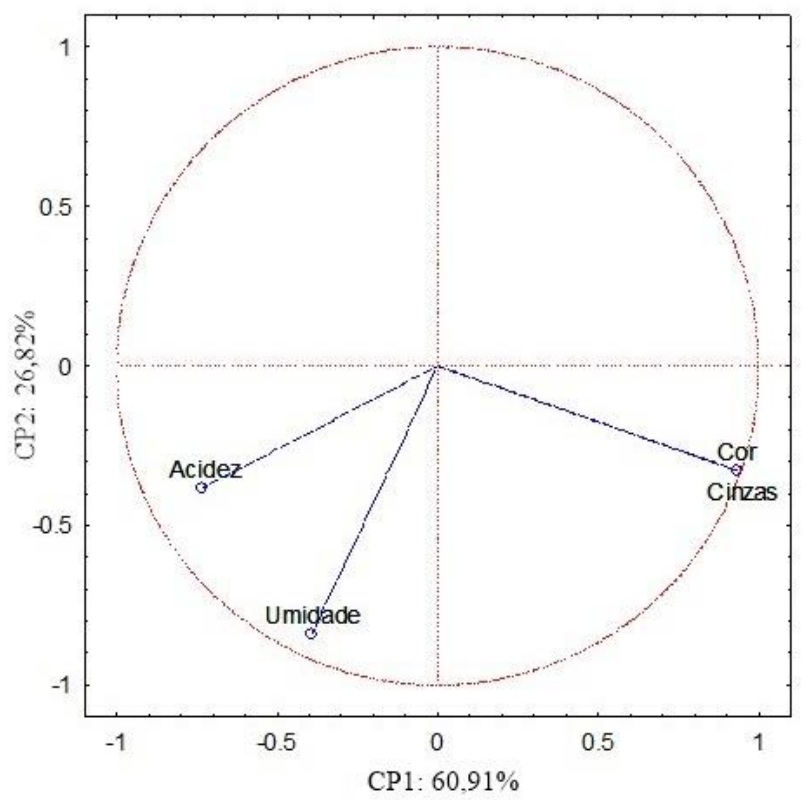

Figura 7: Gráfico de loadings elaborado a partir dos componentes (4 parâmetros físico-químicos) de méis no Pará.

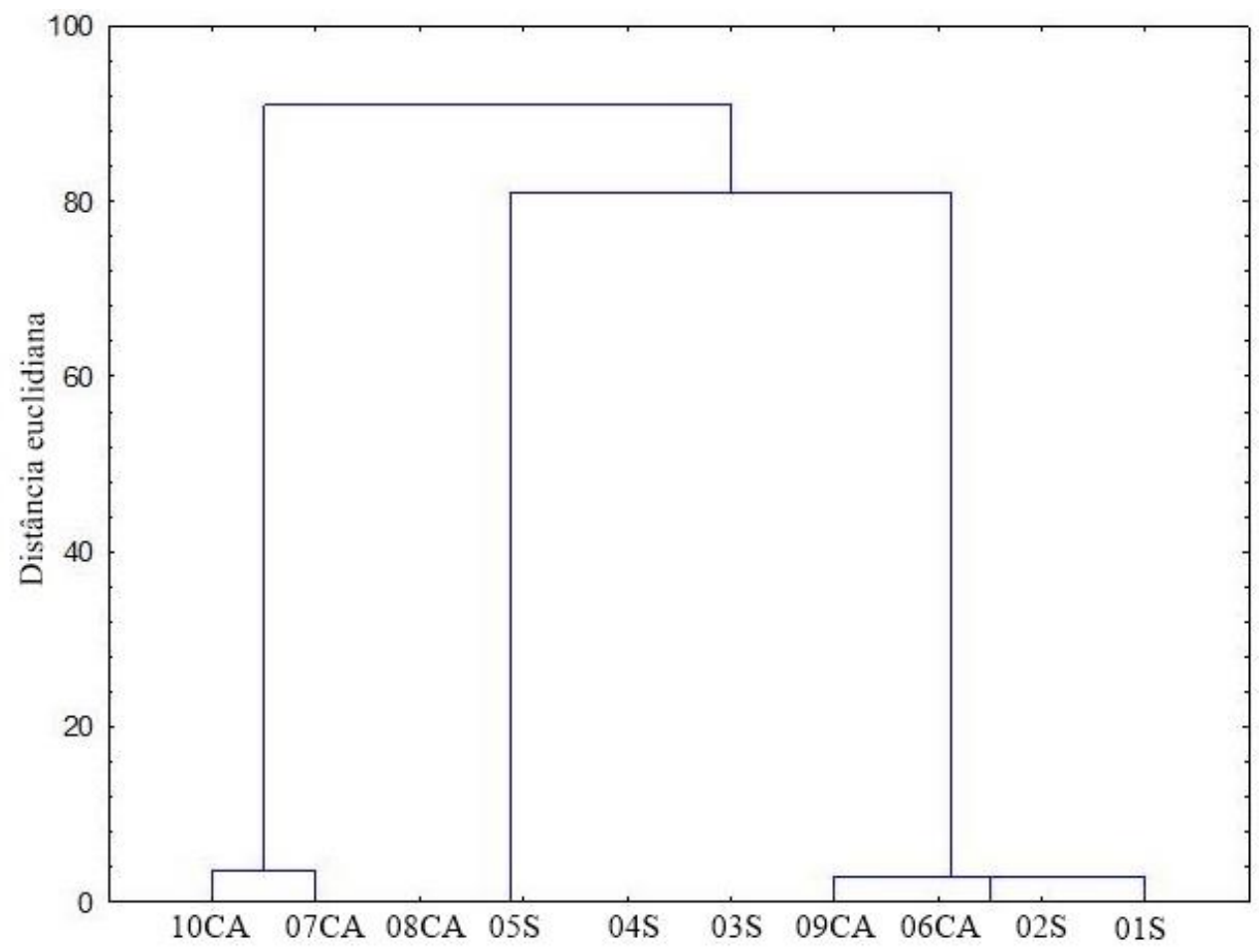

Figura 8: Dendograma utilizando a distância euclidiana das 10 amostras de méis no Pará e os 4 parâmetros físico-químicos.

\section{CONCLUSÃO}

O presente estudo demonstrou que o mel produzido/comercializado na região marajoara ainda necessita passar por adequações nos critérios biológicos, que são aqueles que lhe enquadram como um alimento seguro; esse problema pode estar atrelado diretamente às técnicas de coleta $\mathrm{e}$ processamento do material. Tal situação exige que os apicultores sejam subsidiados por assistência técnico-profissional, de maneira que se obtenha um produto garantido e, consequentemente, de vida útil prolongada. 
Em relação ao seu perfil físico-químico, é importante ressaltar que embora os resultados não sejam expressivamente similares aos definidos pela legislação, isso pode ser um indicativo, ainda precoce, de que os esses resultados poderiam também, sem eximir as possíveis influencias do manejo do produto, ser uma caraterística própria do mel da região, haja vista que as condições climáticas regionais podem ser cruciais na caraterização do produto.

Desta maneira, o referido trabalho teve como umas de suas importâncias dar um "start" para novos estudos que tenham como propósito caracterizar e propor adequações para que o produto da região marajoara possa se encaixar às exigências do mercado externo.

\section{AGRADECIMENTOS}

A universidade do Estado do Pará (Campus XIX, Salvaterra), por disponibilizar seus laboratórios de Tecnologia de alimentos, Microbiologia e Ciências Naturais para o desenvolvimento desta pesquisa.

\section{REFERÊNCIAS BIBLIOGRÁFICAS}

1. Carvalho RG. Apis mellifera: reprodução, polinização e produção de mel [Trabalho de Conclusão de Curso], FAFIBE, Bebedouro. 2010; 36p.

2. Góis GC, Lima CAB, Silva LT, Evagelista-Rodrigues A. Composição do mel de Apis mellifera: requisitos de qualidade. Acta Veterinaria Basilica. 2013;7(2):137-147.

3. Silva CC, Carvalho SE, Carvalho SL, Barbosa CIC, Souza SRRM, Santos SA. Aplicação de testes de adulteração para a avaliação da qualidade dos méis produzidos no nordeste paraense. In: Congresso Brasileiro de Química. Anais eletrônicos. Rio Grande do Norte. 2014; 54.

4. Campos JM, Gomes PWP. Qualidade físico-química e microbiológica de mel de abelhas com e sem ferrão produzidos nos municípios de Soure e Salvaterra - Marajó, Pará [Trabalho de Conclusão de Curso], UEPA, Salvaterra. 2015; 73p.

5. Neves APM, Almeida AMB, Machado AV, Costa RO. Análise físico-química e microbiológica do mel de abelha. Rev Bras Agrotecnol. 2015;5(1):14-18.

6. Abemel. Setor apícola brasileiro em números. 2017.

7. Sousa JM, Souza EL, Marques G, Meireles B, Cordeiro ATM, Gullón B, Pintado MM, Magnani M. Polyphenolic profile and antioxidant and antibacterial activities of monofloral honeys produced by Meliponini in the Brazilian semiarid region. Food Research International. 2016; 84:61-68. doi: 10.1016/j.foodres.2016.03.012

8. Osés SM, Pascual-Maté A, Fernández-Muiño MA, López-Díaz TM, Sancho MT. Bioactive properties of honey with própolis. Food Chemistry. 2016;196:1215-1223, doi: 10.1016/j.foodchem.2015.10.050.

9. IBGE. Instituto Brasileiro de Geografia e Estatística, 2016.

10. Bianchi EM. La miel, características y composición: Análisis y Adulteraciones. Santiago del Estero: UNSE - CEDIA. 1981.

11. AOAC. Sugar and sugar products. Official Methods of Analysis. Association of Official Analytical Chemist. Arlington, VA, USA. 1995; 44 p.

12. Brasil. Ministério da Agricultura, Pecuária e Abastecimento. Defesa Animal. Legislações. Legislação por Assunto. Legislação de Produtos Apícolas e Derivados. Instrução Normativa n. 62, de 26 de Agosto de 2003. Contagem de Bolores e Leveduras.

13. Brasil. Ministério da Agricultura. Instrução normativa $\mathrm{n}^{\circ} 11$, de 20 de outubro de 2000. Estabelece o regulamento técnico de identidade e qualidade do mel. DiárioOficial da República Federativa do Brasil, Poder Executivo, Brasília, DF, 23 out. 2000. Seção 1. p. 1617.

14. Codex Alimentarius. Revised Codex Standard for Honey. Codex STAN 12-1981. Codex Alimentarius Commission. Rev. 2. 2001.

15. Fortuna JL, Nascimento ER, Franco RM. Influência da temperatura de armazenamento sobre a qualidade microbiológica de hambúrgueres crus comercializados em Niterói-RJ. Scientia Plena. 2014;10(5). 
16. Modesto-Junior EN, Gomes PWP, Muribeca AJB, Assis RN, Souza RF. Perfil sensorial e de qualidade do mel comercializado no município de Salvaterra - Ilha do Marajó - Pará. ENCICLOPÉDIA BIOSFERA, Centro Científico Conhecer, Goiânia. 2014;10(19):1448-57.

17. Gomes PWP, Muribeca AJB, Silva MDB, Carneiro JS, Souza RF. Avaliação físico-química e microbiológica de méis de abelhas comercializados no município de Soure - Marajó - Pará. ENCICLOPÉDIA BIOSFERA, Centro Científico Conhecer, Goiânia. 2015;11(22): 2920.

18. Neris MS, Lacerda LM, Rabêl HPSM, Lima LM. Ocorrência de bolores e leveduras em méis comercializados informalmente no Estado do Maranhão. Nutrire. 2013;38:439-439.

19. Mercosul. Resolução $n^{\circ} 15 / 94$. Regulamento técnico MERCOSUL de identidade e qualidade do mel. Buenos Aires: Grupo de Mercado Comum. 1994.

20. Nascimento AS, Marchini LC, Carvalho CAL, Araújo DFD, Olinda RA, Silveira TA. Physical-Chemical Parameters of Honey of Stingless Bee (Hymenoptera: Apidae). American Chemical Science Journal. 2015;7(3):139-149.

21. Souza RF, Pereira SEOL, Santos AS. Adaptação e utilização do reagente de Seliwanoff na análise quantitativa de frutose presente em méis de abelha. In: Reunião Anual da Sociedade Brasileira Para o Progresso da Ciência, 2007. Anais. Belém. 2007; p. 101-102.

22. Azeredo MAA, Azeredo LC. Características físico-químicas dos méis do município de São Fidélis-RJ. Ciência e Tecnologia de Alimentos. 1999;19(1):3-7.

23. Sodré GS. Características físico-química e análises políticas de amostras de méis de Apis mellifera L. da região litoral norte do Estado da Bahia [Dissertação de Mestrado], USP, Piracicaba. 2000.

24. Marchini LC. Caracterização de amostras de méis de Apis mellifera L. 1758 (HYMENOPTERA-APIDAE) do Estado de São Paulo, baseada em aspectos físico-químicos e biológicos. Livre Docência, Escola Superior de Agricultura "Luiz de Queiroz", USP, Piracicaba. 2001.

25. Seemann P, Neira M. Tecnología de la producción apícola. Valdivia: Universidad Austral de Chile, Facultad de Ciencias Agrarias Empaste. 1988.

26. Borsato DM. Composição química, cararacterização polínica e avaliação de atividades biológicas de méis produzidos por meliponíneos do Paraná (Brasil) [Tese do Doutorado] UFP, Curitiba. 2013.

27. Santos DC, Oliveira ENA, Martins JN, Albuquerque EMB. Qualidade físico-química e microbiológica do mel de Apis mellifera comercializado na cidade de Russas, CE. Tecnol. \& Ciên. Agropec. 2011;5(1):41-45.

28. Almeida Filho JP, Machado AV, Alves FMS, Queiroga KH, Cândido AFM. Estudo físicoquímico e de qualidade do mel de abelha comercializado no município de pombal - PB. Revista Verde de Agroecologia e Desenvolvimento Sustentável, Mossoró. 2011;6(3):83-90.

29. Mardia LV, Keni JT, Bibby JM. Multivariate analysis. London: Academic. 1979; 521p.

30. Pamplona BC. Exame dos elementos químicos inorgânicos encontrados em méis brasileiros de Apis mellifera e suas relações físico-biológicas [Dissertação de Mestrado], USP, São Paulo. 1989.

31. Crane E. O livro do mel. 2. ed. São Paulo: Nobel, 1985; 226p.

32. Lacerda JJJ, Santos JS, Santos SA, Rodrigues GB, Santos MLP. Influência das características físico-químicas e composição elementar nas cores de méis produzidos por Apis mellifera no sudoeste da Bahia utilizando análise multivariada. Química Nova. 2010;33(5):1022-1026.

33. Marochi MR. Influência do uso da terra na produção apícola [Dissertação de Mestrado], Unicentro, Irati. 2011. 